\title{
DESAFIOS NA FORMAÇÃO DE PROFESSORES EM UM MUNDO CONECTADO: REPRESENTAÇÕES, PRÁTICAS E LINGUAGENS INOVADORAS
}

\author{
DESAFIOS EN LA FORMACIÓN DOCENTE EN UN MUNDO CONECTADO: \\ REPRESENTACIONES, PRACTICAS E LENGUAGES INNOVADORAS
}

\author{
CHALLENGES IN TEACHER EDUCATION IN A CONNECTED WORLD: \\ REPRESENTATIONS, PRACTICES AND INNOVATIVE LANGUAGES
}

\author{
Rejany dos Santos DOMINICK ${ }^{1}$ \\ Walcéa Barreto ALVES ${ }^{2}$ \\ Marcia Maria e SILVA ${ }^{3}$
}

\begin{abstract}
RESUMO: No curso de Pedagogia da Faculdade de Educação da Universidade Federal Fluminense, temos refletido sobre a emergência de estudos sistemáticos sobre cibercultura e tecnologias informacionais. Realizamos pesquisa, extensão e ensino com o objetivo de ampliar discussões sobre as relações entre cibercultura, educação e formação de professores. Dialogamos com os conceitos inovação pedagógica, inclusão digital, cultura hacker e inteligência coletiva, considerando seus atravessamentos em estudos de linguagem. Apresentamos, neste trabalho, o resultado de 3 rodas de conversa com estudantes universitários e professores do ensino superior: "Tecnologias e Linguagens: Formação docente e múltiplas linguagens no mundo conectado". Identificar os campos de interesse desses grupos tem favorecido a construção de uma oportuna transversalidade temática entre disciplinas já ofertadas. Consideramos necessária a ampliação da oferta regular de cursos na formação inicial e continuada para professores, visando maior clareza e reflexão crítica sobre as implicações das políticas educacionais e práticas docentes no mundo conectado.
\end{abstract}

PALAVRAS-CHAVE: Formação docente. Linguagens. Cibercultura. Inclusão digital.

RESUMEN: En el curso de Pedagogía, de la Facultad de Educación de la Universidad Federal Fluminense, estuvimos reflexionando sobre la premura de estudios sistemáticos sobre cibercultura y tecnologías de la información. Llevamos a cabo investigación, extensión $y$ enseñanza con la finalidad de ampliar las discusiones sobre las relaciones entre la cibercultura, la educación y la formación de maestros. Dialogamos sobre los conceptos de innovación pedagógica, inclusión digital, cultura hacker e inteligencia colectiva, considerando la incursión de éstas en los estudios de lenguaje. En este artículo, presentamos el resultado de 3 círculos de dialogo con estudiantes universitarios y docentes de educación superior: "Tecnologías y lenguajes: formación docente y lenguajes múltiples en un mundo conectado". La identificación de los campos de interés de estos grupos ha favorecido la

\footnotetext{
${ }^{1}$ Universidade Federal Fluminense (UFF), Niterói - RJ - Brasil. Professora Associada. Doutora em Educação (UNICAMP). ORCID: https://orcid.org/0000-0003-0456-4201. E-mail: pedagogiatecnologia@gmail.com

${ }^{2}$ Universidade Federal Fluminense (UFF), Niterói - RJ - Brasil. Professora Adjunta. Doutora em Educação (UFF). ORCID: https://orcid.org/0000-0001-8294-917X. E-mail: walceaalves@id.uff.br

${ }^{3}$ Universidade Federal Fluminense (UFF), Niterói - RJ - Brasil. Professora Adjunta. Doutora em Educação (UERJ). ORCID: https://orcid.org/0000-0002-3838-8229. E-mail: marciamaria@id.uff.br
} 
construcción puntual de una transversalidad temática entre las disciplinas ya ofrecidas. Consideramos necesario la ampliación de la oferta regular de cursos de formación inicial y continua para docentes, con el objetivo de una mayor claridad y reflexión crítica sobre las implicaciones de las políticas educacionales y las prácticas docentes en el mundo conectado.

PALABRAS CLAVE: Formación de maestros. Lenguajes. Cibercultura. Inclusión digital.

ABSTRACT: In the Pedagogy course from School of Education at the Fluminense Federal University, we have been reflecting on the emergence of systematic studies on cyberculture and informational technologies. We conduct research, extension and teaching aiming to broaden discussions about the relationships between cyberculture, education and teacher education. We interact with the concepts such as pedagogical innovation, digital inclusion, hacker culture and collective intelligence, considering their intersections in language studies. We present, in this work, the result of 3 meetings with university students and professors: "Technologies and Languages: teacher education and multiple languages in the connected world". Identifying the fields of interest of these groups has favored the construction of a transversely welcome topic among disciplines already offered. We consider that it is paramount to expand the regular provision of courses in the initial and continuing education for teachers, striving for greater clarity and critical reflection on the implications of educational policies and teaching practices in the connected world.

KEYWORDS: Teacher education. Languages. Cyberculture. Digital inclusion.

\section{Introdução}

Esse texto nasce de iniciativas de pesquisa, extensão e ensino. Identificamos convergências teórico-metodológicas nos nossos estudos sobre cibercultura, linguagens e tecnologias informacionais no âmbito da formação de professores da educação básica e do ensino superior. Questionamos políticas e práticas educacionais que se orientam pelos interesses de mercado no uso e na distribuição de equipamentos e informações para escolas e universidades. Priorizamos a apropriação crítica e cooperativa destes, a produção criativa de conhecimentos em ambientes virtuais e a investigação sobre os processos interativos nas redes sociais.

Mantemos diálogo com escolas públicas no estado do Rio de Janeiro e com estudantes de cursos de licenciatura da Universidade Federal Fluminense. Sabemos que artefatos tecnológicos informacionais e a rede de internet, também denominados como tecnologias digitais da informação e da comunicação (TDIC), chegaram às escolas devido, especialmente, a incentivos governamentais que foram justificados pelo discurso de inclusão digital e maior qualidade para os processos de ensino-aprendizagem. Contudo, além das questões que 
envolvem aquisição, distribuição de equipamentos para as instituições de ensino e disponibilização do acesso à rede, temos identificado que narrativas de professores e estudantes têm interesse por formação tanto para o uso de equipamentos como também para a apropriação crítica, autônoma e autoral do mundo tecnológico e digital em sua sala de aula. Está implicado nesses interesses, também, o debate sobre as múltiplas linguagens que materializam objetiva e subjetivamente as relações interpessoais no ciberespaço, aspectos indispensáveis de serem abordados nas formações de professores.

Visando ampliar os debates sobre o tema, durante a Agenda Acadêmica 2018 , realizamos uma primeira Roda de Conversa que denominamos "Formação docente e múltiplas linguagens no mundo conectado". Buscamos ampliar o debate e socializar as produções docentes e discentes, tendo como foco o trabalho docente na sala de aula e os modos de apropriação pedagógica das tecnologias digitais. Como as mídias digitais estão dialogando com a diversidade cultural na e da sala de aula? Participaram estudantes de diferentes cursos de graduação, pós-graduação e professores da Universidade. Uma docente do ensino superior, com uma postura crítica ao conceito de inovação pedagógica, considerou pertinente e fundamental o nosso enfoque: firmar uma perspectiva reflexiva, ampliando o debate para além do uso de equipamentos informacionais.

Defendemos que uma pedagogia inovadora é aquela que desloca o professor do centro condutor de todo o processo, rompendo com o papel de transmissor de conteúdos, como se concebia nos velhos esquemas das escolas modernas. Reconhecemos inovadora uma perspectiva de professor mediador, propositivo, provocador, pesquisador, instigador da reflexão e da autoria. Esse tipo de professor propõe questões, desenvolve debates, abre campos de experimentação e reflexão com os estudantes.

O compartilhamento, a colaboração, a abertura às singularidades dos estudantes, além da sistematização individual e coletiva dos conhecimentos construídos leva à apropriação inovadora de artefatos tecnológicos digitais e analógicos. Nessa perspectiva, vão se realizando rupturas com o modelo de falar-ditar do mestre, abrindo espaço para a participação genuína que, para Silva (2010, p. 44), é a "participação sensóriocorporal e semântica e não apenas mecânica, capaz de superar a centralidade da modalidade tradicional de aprendizagem, em favor da aposta na modalidade interativa, da dinâmica comunicacional da cibercultura e da educação autêntica". Para nós, uma pedagogia inovadora precisa articular a dialogia entre

${ }^{4}$ A Agenda Acadêmica é um evento anual que tem o objetivo de apresentar a produção desenvolvida na UFF em suas três grandes áreas de atuação - ensino, pesquisa e extensão. Disponível em: http://www.uff.br/?q=events/agenda-academica-uff-2018. Acesso em: jul. 2019. 
docentes e discentes e destes com os conhecimentos que estão disponíveis em diversas mídias. As linguagens se tornam, portanto, o cerne do processo de ligar pessoas, artefatos e saberes.

Realizamos, em 2019, mais duas rodas de conversa sobre a mesma temática, com o mesmo título: "Formação docente e múltiplas linguagens no mundo conectado". Tivemos a participação de alunos de graduação em Pedagogia (a maioria), Letras, Enfermagem, Matemática e História. Havia, também, alunos de pós-graduação que são docentes na educação básica. São essas duas rodas, linkadas por nossas experiências de docentespesquisadoras-formadoras, que articulam as discussões deste texto.

Ao final de cada uma das rodas, provocamos: "Proponham dois temas que vocês gostariam de discutir na formação de professores. Indiquem subtemas para desdobramentos”. Os participantes produziram registros escritos, compartilhados no grupo, na forma de cartazes, suscitando questões com foco na formação docente.

Para apresentarmos e refletirmos sobre as propostas feitas pelos estudantes de graduação, traçamos, neste texto, o seguinte percurso: problematizamos o uso das tecnologias informacionais a partir das linguagens e de sua apropriação nos espaços escolares; abordamos a roda de conversa como uma tecnologia social que possibilita tanto o debate como a coleta de dados; apresentamos os dados quantitativos e qualitativos coletados junto aos participantes das duas rodas de conversas; e analisamos possibilidades para incluir a temática nos cursos de licenciatura a partir das propostas apresentadas pelos participantes.

\section{Problema e olhares teóricos}

O que levamos em consideração ao identificarmos a emergência do aprofundamento do debate que articule estudos sobre a formação de professores da educação básica e superior a respeito das diferentes configurações que constituem a virtualidade das relações humanas em ligeira expansão no Brasil e nos demais países, sobretudo a partir do advento da internet, das redes wifi e também dos smartfones?

Encontramos no Atlas da Violência $2019^{5}$ o perfil de um país cuja desigualdade social e econômica atinge índices alarmantes. A falta de oportunidade que leva em torno de $23 \%$ de jovens ao abandono dos estudos, segundo dados de 2017, o alto índice de violência letal contra os jovens, entre tantos outros problemas que dificultam o desenvolvimento do país, nos

${ }^{5}$ Organizado pelo Instituto de Pesquisa Econômica Aplicada e o Fórum Brasileiro de Segurança Pública no Brasil. 
levam a repensar o fracasso escolar e o papel da universidade em formar professores conscientes da responsabilidade política e social a ser materializada para redimensionar as práticas pedagógicas de modo que favoreçam a inclusão social.

Lèvy (2010, p. 12) nos instiga a sermos mais abertos à novidade, buscando compreender a expansão das novas redes de comunicação sob a perspectiva das "mudanças qualitativas para a vida social e cultural”. Sabemos, contudo, do domínio que o capital exerce sobre o ciberespaço e dos seus interesses em alimentar o mercado, corroborado, inclusive, por algumas políticas internacionais, contra as quais a Organização das Nações Unidas (ONU) vem se posicionando (SILVA; ANTUNES; VOSS, 2019). Sabemos que a superação da desigualdade social não faz parte da agenda neoliberal. No contexto educacional identificamos discursos sobre a eficiência e eficácia, bem como políticas de inovação tecnológica e educacional que partem da lógica do capital. Diante desse panorama político, é preciso problematizar de maneira propositiva os modos de ler, interagir e produzir conhecimentos científicos e tecnológicos, dando a ver inclusive os perigos das possíveis apropriações que intensificam a exclusão social.

Castells, em julho de 2019, esteve na cidade de Niterói participando do Seminário Internacional Educação, Cultura e Tecnologia: a escola do século $\mathrm{XXI}^{6}$, com o objetivo de intensificar o debate, entre profissionais da educação, sobre comunicação em rede, tecnologias digitais e produção de conhecimento na contemporaneidade. Ele afirmou que a educação tem papel fundamental no desenvolvimento econômico, profissional, social e pessoal, pois é um elemento chave para entendermos e questionarmos a própria vida, é base para que existam "pessoas conscientes informadas, capazes de tomar decisões por si mesmas”. Ressaltando a quantidade de informações disponíveis, afirmou que o problema não está na quantidade, mas no domínio dos caminhos de busca, do manejo, do tratamento e da compreensão das informações. Segundo ele, o educador tem papel central como agente de transformação da qualidade de conectividade das futuras gerações. $\mathrm{O}$ aparato tecnológico não substitui o trabalho do mediador.

O palestrante explicitou suas preocupações com a falta de foco dos estudantes dada a quantidade de informações e a velocidade com que circulam. Castells nos chama a atenção para o fato de haver nas crianças e jovens grande capacidade de lidar com muitas tarefas simultâneas e de gerar novas combinações a partir de diferentes fontes de informação. Ele explicitou sua compreensão de que "aprender em comunidade", "personalizar a

\footnotetext{
${ }^{6}$ Organizado pela Fundação Arte de Niterói.
} 
aprendizagem" e "estabelecer relações com as experiências de vida" são aspectos potencializadores da inovação do processo educacional na contemporaneidade, e apontou que cabe ao professor se aperfeiçoar para lidar com o perfil dos estudantes, que já estão em conexão com o mundo virtual no cotidiano, independentemente de a escola incorporar ou não metodologias de inclusão tecnológica.

As instituições necessitam se preparar para transformar as relações entre professores e alunos, redimensionando papéis, repensando formas de interação e conectividade. Em suma, o sociólogo nos instiga a refletir sobre e a debater as políticas e práticas de formação de professores na sociedade da informação.

No que diz respeito ao tratamento e à compreensão das informações que circulam em quantidade diante dos olhos dos estudantes navegadores do ciberespaço, destacamos não somente os diferentes modos de leitura que concorrem no mundo contemporâneo sobre os quais discorre Santaella (2013), ao tratar dos processos de comunicação ubíqua, quando os aparelhos celulares constituem-se como instrumento de comunicação síncrona e assíncrona, suporte para inúmeras possibilidades de produção de textos e interações diversas através de jogos, redes sociais, e-mails, dentre outras, além de permitir o acesso quase instantâneo a um mundo de informações. É uma fonte móvel que acompanha o usuário.

A gama de possibilidades interativas transforma os processos de formação do leitor, gerando novas demandas educacionais, em um panorama onde nem mesmo velhas demandas foram superadas. Como pesquisar, selecionar, tratar e compreender as informações relevantes no universo cibercultural? Como formar leitores críticos, sujeitos conscientes informados?

Os estudos bakhtinianos sobre linguagem contribuem para a qualidade das ações de seleção, combinação e tratamento das informações, viabilizando a compreensão do caráter ideológico dos textos circulantes, bem como das estratégias de controle, persuasão do leitor impregnado nos jogos de linguagem produzidos na composição entre as imagens, os textos, os vídeos e outras linguagens que materializam os conteúdos no ciberespaço. A compreensão da não neutralidade nas interações verbais, das estratégias discursivas de captação de um público consumidor das ideias e opiniões determinadas, exige aprofundamento nos estudos sobre as produções discursivas nas redes sociais. "As relações de sentido que se estabelecem entre dois enunciados" (FIORIN, 2006, p. 19) é o que Bakhtin denomina dialogismo:

Um objeto qualquer do mundo interior ou exterior mostra-se sempre perpassado por ideias gerais, por pontos de vista, por apreciações dos outros; dá-se a conhecer para nós desacreditado, contestado, avaliado, exaltado, categorizado, iluminado pelo discurso alheio (FIORIN, 2006, p. 19).

RIAEE - Revista Ibero-Americana de Estudos em Educação, Araraquara, v. 15, n. esp. 2, p. 1629-1651, ago. 2020. e-ISSN: $1982-5587$. 
Nesse sentido, a formação de docentes no mundo conectado não pode prescindir do estudo dos processos discursivos implicados no conteúdo dos textos, na forma dos textos, nas múltiplas linguagens que os constituem.

\section{Linguagens inovadoras: concepções e práticas}

Do campo dos estudos das linguagens e das inovações pedagógicas optamos por ressaltar perspectivas que nos parecem abrir caminhos para a transformação das condições em que o trabalho didático-pedagógico possa se tornar inovador. No contexto da educação superior, Cunha (2016) trata como "ruptura paradigmática" a inovação.

Explora esse conceito a partir da relação entre pedagogia, epistemologia e cultura. Critica a concepção positivista de conhecimento que, na busca de neutralidade, ordem, controle... afasta das aulas emoção, autoria, dúvida, pergunta... Questiona os discursos sobre inovação pedagógica que não realizam uma efetiva mudança, dado que não se redimensionam as bases em que sustentam as práticas pedagógicas. Para ela é necessária "a mudança da cultura do ensinar e do aprender" (CUNHA, 2016, p. 92), o que não se constrói através da inclusão de novos recursos tecnológicos e digitais, mas compreendendo os novos modos de ensinar e aprender que esses meios viabilizam.

Cunha (2016) reflete que os modos de circulação de informações se modificaram, o papel do professor mudou, os modos de ler, estudar, conhecer foram alterados. O foco deixa de ser a transmissão e passa a ser a articulação entre o aprendiz e o conhecimento. Para ela, a aula se constitui pela abertura a outros tempos-espaços de aprendizagem, considerando a heterogeneidade, a interculturalidade.

A escola contemporânea, em consequência, ganha outros sentidos a serem investigados e compreendidos. Inovar seria inverter a relação teoria-prática. Sem hierarquias nem linearidades, rompemos com a noção de currículo como somatório de disciplinas. 


\section{As escolas e o "mundo conectado"}

O Censo escolar (INEP, 2018) ${ }^{7}$ indica-nos que hoje há mais acesso às tecnologias informacionais nas escolas do que há dez anos, embora nossas práticas e pesquisas nos mostrem que, no cotidiano da sala de aula, há docentes e alunos que não dialogam de forma inclusiva com os artefatos disponíveis, o que nos leva a pensar sobre a emergência de políticas e práticas, que, para além do acesso, busquem qualificar os modos de apropriação do aparato tecnológico a favor da transformação da educação.

Sabemos que a proibição do uso do celular sob pretexto de não dispersar os alunos do foco das aulas não é uma estratégia incomum. Identificamos, nos espaços com laboratórios de informática, que não há regularidade no funcionamento dos computadores nem da internet. Também parecem ser raros os docentes que realizam atividades com os celulares dos alunos ou no laboratório de informática.

A falta de redes wi-fi acessíveis aos alunos e também o desconhecimento das possibilidades de tornar essas atividades parte do processo de ensinar e aprender articuladas às inúmeras formas de interação, já preponderantes na sociedade em diferentes espaços não escolares, são elementos que deflagram o distanciamento dos processos educativos formais do contexto da cibercultura. Há alunos da graduação do curso de Pedagogia que expressam desconforto, quando convidados a navegar, a ambientar-se e a realizar atividades em plataformas virtuais de aprendizagem com o objetivo de problematizar esse espaço enquanto recurso didático. Dados de nossas pesquisas estão disponíveis em artigos publicados por Coaracy e Alves (2018), Dominick e Silva (2013), Dominick e outros (2018), Dominick e Alves (2018) e Silva (2018).

Como ocorre com alunos da educação básica, também na universidade a falta de artefatos pessoais (celulares com rede wifi potente, laptops ou de mesa), mesmo havendo laboratório de informática na Faculdade de Educação, dificulta a realização de atividades nesses ambientes ou a partir deles. Soma-se a isso uma crítica contundente de muitos ao que supõem se aproximar do modelo de cursos a distância, em muitos casos produzidos de maneira aligeirada, comumente ambientados em plataformas virtuais.

O Censo Escolar (INEP, 2018) aponta que mais de 90\% das unidades federais e mais de $70 \%$ das escolas estaduais que oferecem o ensino fundamental têm recursos de laboratório

${ }^{7}$ Instituto Nacional de Estudos e Pesquisas Educacionais Anísio Teixeira. Resumo Técnico: Censo da Educação Básica 2018 [recurso eletrônico]. - Brasília: Instituto Nacional de Estudos e Pesquisas Educacionais Anísio Teixeira, $2019 . \quad 66 \mathrm{p} . \quad$ Disponível em http://download.inep.gov.br/educacao_basica/censo_escolar/resumos_tecnicos/resumo_tecnico_censo_educacao _basica_2018.pdf. Acesso em: jul. 2019. 
de informática, de internet ou de banda larga disponíveis. Com relação às redes municipais, que hoje atendem majoritariamente ao primeiro segmento e à educação infantil, percebemos, no gráfico, que a situação ainda é precária, pois apenas 35\% das escolas têm laboratório de informática, 55.9\% contam com acesso à Internet e 43.3\% possuem acesso de Banda Larga (Imagem 1). Nas escolas municipais do município do Rio de Janeiro e de Niterói, há laboratórios de informática ou equipamentos do tipo Tablet que podem ser usados em sala de aula por alunos e professores. Entretanto, sabemos que no Município de São Gonçalo, origem da grande maioria de nossos alunos na graduação em Pedagogia, não há laboratórios de informática nas escolas.

Imagem 1 - Recursos relacionados à infraestrutura disponível nas escolas do ensino fundamental - Brasil - 2018

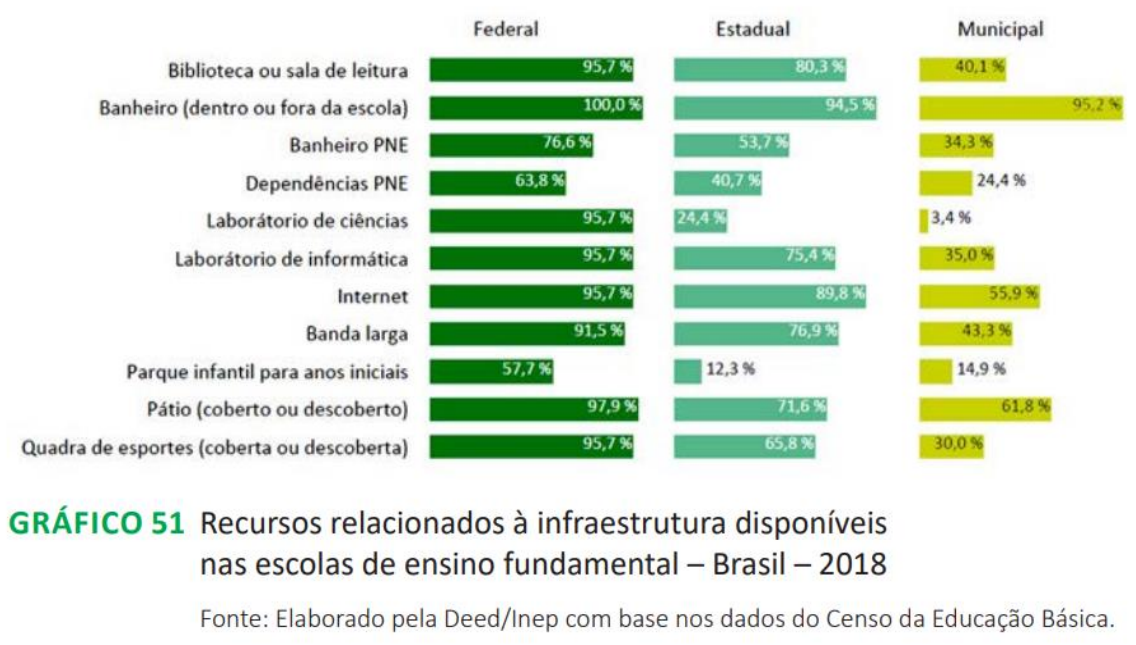

Fonte: Censo Escolar - Resumo Técnico - Censo da educação básica 2018 - INEP (p. 54) ${ }^{8}$

Não obstante a falta de equipamentos e de internet nas escolas e nas universidades, crianças e jovens da educação básica estão participando do mundo conectado por meio de acesso doméstico ou pelo celular. Estamos vivenciando o que Castells (1999) denomina sociedade da informação, que surge a partir das décadas de 1960 e 70. Trata-se de "um novo mundo", no qual sociedade, economia e cultura se interligaram por meio dos avanços das tecnologias da informação e da comunicação, fazendo surgir uma sociedade em rede, uma sociedade informacional. 
Contudo, a maioria das crianças, jovens e seus pais não têm informações que possibilitem a inclusão digital com garantia de um mínimo de segurança no acesso aos conteúdos virtuais ou mesmo no processo de disponibilização de conteúdos privados online. Identificamos tanto alunos quanto professores que não agem nos espaços como sujeitos interagentes (CASTELLS, 2002).

Embora o acesso aos artefatos e mesmo à rede de computadores tenha crescido, a consciência sobre limites e possibilidades do/no ciberespaço não têm sido tematizados de forma sistemática nos cursos de licenciatura. Pouco se percebe nas escolas das redes públicas formação continuada sistemática que possibilite aos docentes a apropriação da cibercultura a favor de uma inclusão digital pensada do ponto de vista do professor reflexivo, da diversidade e da cultura da partilha do ponto de vista de uma racionalidade baseada na ética hacker (BONILLA; PRETTO, 2015), que busca o compartilhamento de informações livremente, possibilitando a construção das novas formas de relacionamento social.

Acreditamos que seja papel da escola contribuir discutindo e até produzindo conteúdo para as mídias eletrônicas. Esse é um caminho de formação para a cidadania que deve se articular aos princípios da tecnologia social ${ }^{9}$ (FRANCO; SÁENZ, 2013), em especial no que se refere à valorização dos conhecimentos locais.

Visando nos apropriar do movimento de produção sobre o tema, realizamos uma busca no SCIELO com os descritores "digital", "escola" e "professor". Foram encontrados 15 resultados, em língua portuguesa, no período entre 2014 e 2017. Em busca no Google Acadêmico, com os mesmos descritores, encontramos mais de 168.000 resultados. Contudo, o fato de haver uma forte produção acadêmica não significa que a discussão é efetiva nos cursos de licenciatura no Brasil e muito menos no cotidiano das salas de aula. Freitas (2015) narra seu estranhamento quando, ao chegar a Portugal para doutoramento, identifica que os professores portugueses do curso

nas aulas dos Seminários de acesso ao doutoramento em Ciências da Educação da Universidade da Madeira (UMa), abordavam a vanguarda das discussões sobre a Sociedade da Informação e o seu impacto no processo educacional. Somou-se ao ocorrido a experiência inversa relativa ao fato de não ter detectado na literatura brasileira estudada, quando do desenvolvimento das atividades de elaboração de artigos científicos e outras, as discussões acerca da temática objeto de estudo [...] (p. 5).

${ }^{9}$ Em texto publicado em: https://periodicos.fclar.unesp.br/iberoamericana/article/view/11647. Desenvolvemos um pouco mais o tema. 
Santos (2009) realizou levantamento sobre os trabalhos apresentados, entre 2000 a 2008, nos GTS Formação de Professores e Educação e Comunicação da ANPED (Associação Nacional de Pós-Graduação e Pesquisa em Educação), relativos ao tema "formação dos professores para o uso das tecnologias digitais". Esse trabalho nos ajuda a refletir sobre como, no início do século XXI, andavam as discussões. A autora afirma:

É fato que as exigências postas pela sociedade contemporânea, permeada de tecnologias, estão pautando uma nova dinâmica para a atuação docente e questionando a eficiência das políticas públicas de formação de professores para enfrentarem essa realidade. Se, por um lado, a sociedade da informação exige a apropriação dos conhecimentos nessa área pelo professor, por outro, as políticas públicas ainda não conseguiram incluir totalmente as escolas no mundo digital e, nos processos formativos de docentes, tais questões não encontram muito espaço. Assim, o professor tem dificuldade de conceber as tecnologias da informação e comunicação (TICs) como condição de produção e, paradoxalmente, sintonizar-se com a cultura digital dos alunos (SANTOS, 2009, p. 02).

Sete anos antes, Pretto (2002, p. 130) escreveu:

Não podemos, portanto, nos contentar com propostas de introdução dessas tecnologias na escola como se elas fossem, por si sós, as transformadoras de todo esse processo que está superado e que não dá conta das transformações do mundo contemporâneo: um planeta em movimento, não os conhecidos, tradicionais e harmônicos movimentos de rotação e translação, mas movimentos mais complexos, que fazem o mundo, também, mais complexo (p. 130).

Ele analisou, em seu texto, que nasceu de uma fala na $24^{\text {a }}$ Reunião da $\mathrm{ANPEd}^{10}$, as políticas governamentais para a inclusão das tecnologias informacionais nas escolas e concluiu que

É desse novo contexto que emerge o papel de um novo professor, não mais um repassador de informações, que se satisfaça com certificações aligeiradas. Esse turbilhão em movimento exige um outro profissional, que não se contente com o simples fornecimento e recebimento de informações distribuídas através das TIC, mas que aja como liderança de múltiplos processos que valorizem o trabalho docente e a sua profissão, em ricos processos de desverticalização do sistema (2002, p. 130).

Como podemos perceber, a discussão não é nova. Há uma produção significativa sobre o tema, mas, em muitos espaços de formação de professor, ainda estamos engatinhando com relação a incluir os diferentes ângulos da temática nas dinâmicas das disciplinas e possibilitar,

${ }^{10}$ ANPEd - Associação Nacional de Pós-Graduação e Pesquisa em Educação. 
ao licenciando, uma formação profissional dialógica, considerando as tecnologias digitais na sala de aula.

$\mathrm{Na}$ Faculdade de Educação da UFF, recentemente, um grupo de professores tem proposto, para além das aulas nas disciplinas ministradas e dos projetos específicos coordenados, ações que possibilitem a construção de experiências instituintes (Linhares, 2001), reflexões teóricas e práticas sobre inovações pedagógicas que conectem pessoas, artefatos e saberes via interações de ensino-aprendizagem mediante rodas de conversa.

\section{As rodas de conversa como metodologia}

Segundo Warschauer (2001), uma das características de uma roda de conversa é "reunir os indivíduos que trazem histórias de vida diferentes e maneiras singulares de pensar e sentir" (p. 46). Dessa forma, a partir dos encontros, num processo fecundo de trocas, entrelaçamentos e aproximações gera-se vida mediante a produção de sentidos. De forma análoga, a autora afirma: "Do encontro, nasce o ovo. Das intersubjetividades nasce o grupo" (p. 46). Corroborando com essa perspectiva, nas rodas de conversa propostas, buscamos pistas da diversidade de interesses e a criação de sentidos, de vínculos entre os sujeitos para o desenvolvimento de uma consciência de grupo, para a "corporificação" de um saber coletivo, construído, dialogado. Tal momento de troca entre os participantes, o sentar-se em círculo, a visão mútua um do outro tem sido, para nós, um convite à fala e à escuta, produzindo experiências intersubjetivas. Sabemos não se tratar de um processo simples, "pois conseguir ouvir o que o outro tem a nos dizer, não só quando concordamos, mas principalmente, quando dele discordamos, é tarefa muito difícil, porém muito útil [...]” (WARSCHAUER, 2001, p. $51)$.

Na perspectiva de uma pedagogia inovadora, a fala dos discentes, valorizada na roda, produz fissuras na perspectiva de professor como único detentor do saber. As vozes são potencializadas no círculo, criando outra cultura política. A roda de conversa também nos conecta à proposta freiriana de círculo de cultura. Criado na década de 1960 com o objetivo de alfabetizar adultos para além da leitura da palavra, tal prática também tira o professor do seu lugar de poder e de controle e possibilita interações mais dialógicas e democráticas tanto no que se refere ao relacionamento entre os sujeitos, quanto ao conteúdo tratado, pois as contrapalavras dos participantes entram na roda sem a prepotência que hierarquiza os saberes. Constrói-se uma leitura coletiva de mundo. 
Nos círculos de cultura, busca-se, antes de tudo, a potência da palavra compartilhada, gerando interesse por conhecer, corresponsabilidade sobre a vida em grupo, inquietação e questionamento em relação ao pré-estabelecido como verdade. Pensando sobre as diversas culturas como construção social, concebemos a importância de um trabalho voltado para a formação dessa consciência, deslocando-nos do lugar de aceitação da realidade, passando a nos implicar com profundidade na observação e reflexão sobre a vida. Estamos buscando a formação de professores reflexivos (SCHÖN, 1983), aqueles capazes de produzir "conhecimento em ação". Contudo, para uma prática reflexiva com construção de conhecimentos implicados, é preciso que a experiência produza reflexão e a análise potencialize o aprimoramento do fazer docente.

Em um movimento coletivo e coletivizador de múltiplas vozes e corpos que se tramam, emerge da problematização humana em diálogo circular a intersubjetivação que afeta cada um e muitos. Fazer a crítica da cultura e da cibercultura é reelaborar e reelaborar-se no mundo, humanizando-se.

Em uma roda de conversa ou em um círculo de cultura podemos assumir que todo processo educativo tem um caráter político, uma política de partilha. Sabemos que "não há nem jamais houve prática educativa em espaço e tempo nenhum de tal maneira neutra, comprometida apenas com idéias preponderantemente abstratas e intocáveis" (FREIRE, 1992, p. 78). Precisamos assumir o caráter político de todas as ações educacionais, as presenciais e aquelas que acontecem com mediações das diversas tecnologias, pois há políticas emancipadoras e há também as que reproduzem a lógica dos dominadores.

\section{Diálogos em pesquisa - resultados e análise}

Entendendo a potencialidade do diálogo para a construção de saberes e práxis, propusemos, no ano de 2019, duas rodas de conversa no âmbito da Faculdade de Educação/UFF, dando continuidade às ações que vínhamos desenvolvendo sobre o tema "Tecnologias e Linguagens: formação docente e múltiplas linguagens no mundo conectado".

Esses eventos ocorreram no mês de abril, nos turnos matutino e noturno. Foram, ao todo, 79 participantes, sendo 43 pessoas no turno noturno (Roda de conversa 2) e 36 no turno matutino (Roda de Conversa 3).

As rodas de conversa se iniciaram com as apresentações dos participantes, a fim de que o grupo pudesse estabelecer conhecimento mútuo. Em seguida, foram explanadas algumas reflexões sobre o tema a partir das pesquisas e experiências das docentes 
proponentes. Após a primeira hora de conversa, a roda começou a girar pelas reflexões dos estudantes presentes. A roda "constitui-se num momento de diálogo, por excelência, em que ocorre a interação entre os participantes do grupo, sob a organização do coordenador, o professor" (WARSCHAUER, 2001, p. 47). Nós, docentes-pesquisadoras, éramos a figura "do coordenador do grupo", que tinha o papel de dinamizar e potencializar a discussão, buscando aprofundar a temática e alcançar o objetivo do diálogo.

A roda foi enriquecida com perguntas, debates, provocações reflexivas, de modo que as vozes de todos os participantes ressoaram em todos nós, mediante a troca de experiências, indagação sobre expectativas, descoberta de possibilidades e problematização de vivências tanto no percurso pessoal quanto nos percursos acadêmicos e profissionais.

O último momento da roda ocorreu após uma pausa, quando compartilhamos um coffebreak produzido de forma comunitária, o que proporcionou momentos de descontração e de maior aproximação.

O trabalho foi retomado com a proposta de formação de grupos, provocados a realizar uma produção a partir da questão geradora: "Proponham dois temas que vocês gostariam de discutir na formação de professores. Indiquem subtemas para desdobramentos”. Essa proposta foi embasada na concepção apresentada por Hernàndez e Ventura (1998). Propusemos aos participantes que fizessem uma espécie de índice primário ${ }^{11}$, indicando temáticas e tópicos que consideravam importantes serem abordados na formação docente. Os grupos produziram cartazes que se constituíram como importante registro e sistematização dos pontos discutidos durante a roda de conversa, servindo como fonte de pesquisa para levantamento de elementos considerados relevantes e significativos pelos participantes.

Os diálogos potencializaram reflexões sobre a temática das tecnologias, da inclusão digital, da formação docente no mundo conectado e das múltiplas linguagens que perpassam os processos comunicacionais contemporâneos. A partir das trocas ocorridas e da produção dos índices expostos nos cartazes foi possível captar algumas representações sobre o interesse do grupo para discutir na formação docente.

Os quadros que apresentamos a seguir apresentam os conteúdos dos cartazes e explicitam o que entendemos enquanto vontade política dos participantes que integraram as conversas e os diálogos dinamizados.

${ }^{11}$ O índice, na perspectiva de Hernàndez e Ventura (1998), é uma importante estratégia que auxilia a estruturação e organização do processo de aprendizagem e do projeto de trabalho em si. Mediante a objetivação de temas de estudo e detalhamento de subtemas, é possível delinear etapas e recursos para a organização de esquemas de ação, que proporciona a autonomia e engajamento no processo educativo. $\mathrm{O}$ índice primário consistiria na primeira etapa de exploração sobre a temática proposta, onde se levantam perspectivas prospectivas de pesquisa e análise (p. 76-80). 
Quadro 1 - Produção dos estudantes que participaram da Roda de conversa 2

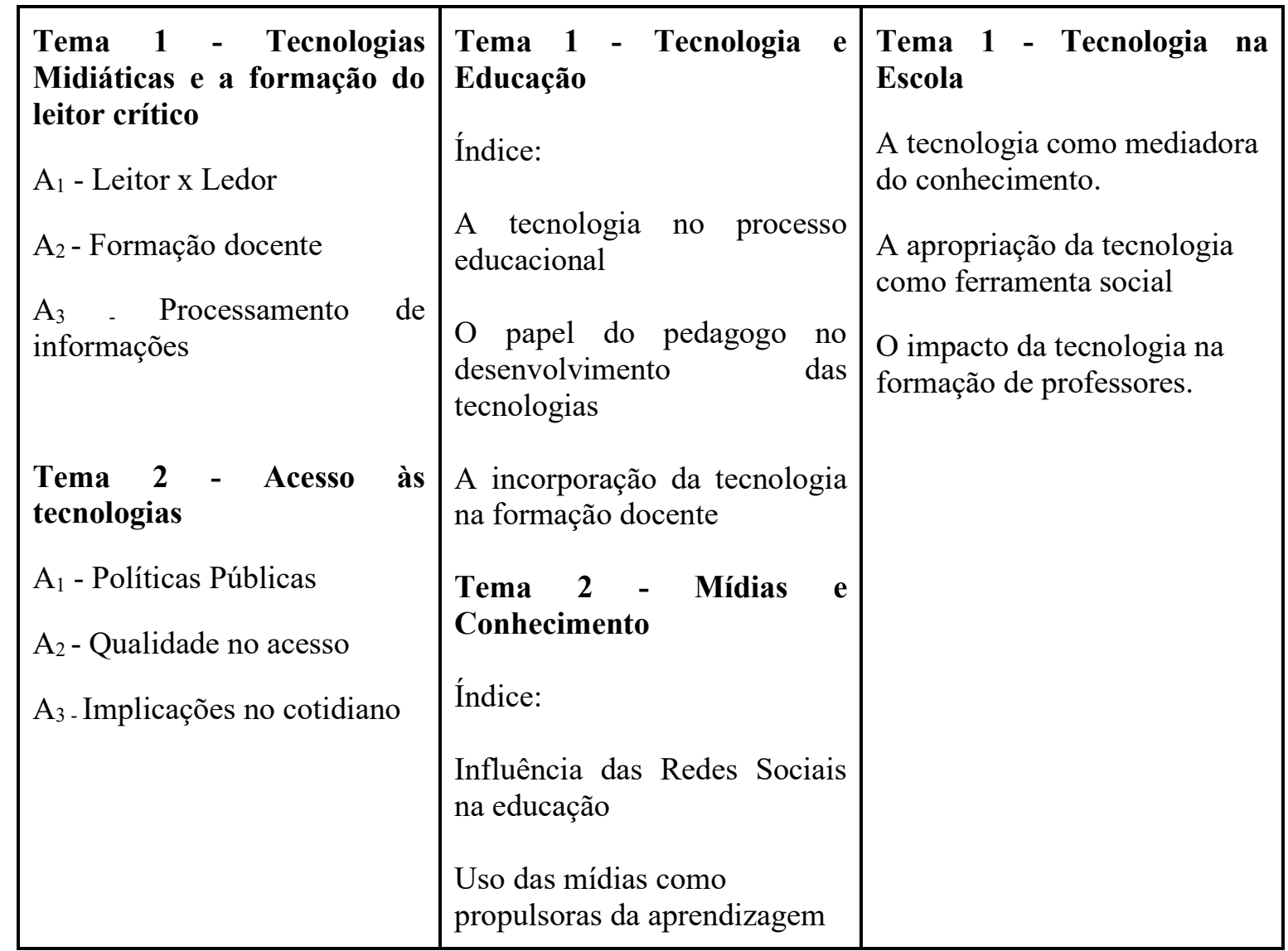

Fonte: Elaborado pelas autoras

Quadro 2 - Produção dos estudantes que participaram da Roda de conversa 3

\begin{tabular}{|c|c|}
\hline $\begin{array}{l}\text { Tema 1: Tecnologia Social como } \\
\text { metodologia de ensino } \\
\text { - Inclusão social } \\
\text { - } \quad \text { Transformação da realidade } \\
\text { - Participação coletiva }\end{array}$ & $\begin{array}{l}\text { Tema 1: Introdução às tecnologias digitais } \\
\text { Índice: } \\
\text { 1.1. Desdobramentos na educação } \\
\text { básica } \\
\text { 1.2. Conceitos contemporâneos }\end{array}$ \\
\hline $\begin{array}{l}\text { Tema 2: Implicações do mundo virtual na } \\
\text { realidade escolar } \\
\text { - } \text { Ciberbullying } \\
\text { - } \text { Transformação do olhar docente } \\
\text { - Conhecimento das comunidades } \\
\quad \text { virtuais }\end{array}$ & $\begin{array}{l}\text { Tema 2: Políticas de acesso e permanência } \\
\text { das tecnologias nos processos formativos } \\
\text { Índice: } \\
\text { 2.1. Desmistificação do uso das novas } \\
\text { tecnologias nas práticas docentes } \\
\text { 2.2. Currículo e tecnologias }\end{array}$ \\
\hline
\end{tabular}

Fonte: Elaborado pelas autoras

Muitas leituras podem ser aprofundadas sobre o material coletado em nossa proposta, mas em um primeiro momento de análise é possível observar o fato de que, a partir da roda de 
conversa, os sentidos produzidos tiveram uma forte relação com questões relativas ao fazer docente na sala de aula. Os professores em formação inicial e continuada dinamizaram os diálogos e tornaram visíveis nos cartazes a atenção voltada a aprendizados que se conectam à ação, à prática do professor e sua relação com a escola. Nos temas e índices propostos, temos: “Tecnologia e Educação", "A tecnologia no processo educacional”; "O papel do pedagogo no desenvolvimento das tecnologias"; "Tecnologia na Escola", "A tecnologia como mediadora do conhecimento", "A apropriação da tecnologia como ferramenta social"; "Mídias e Conhecimento", "Influência das Redes Sociais na educação", "Uso das mídias como propulsoras da aprendizagem"; "Tecnologia Social como metodologia de ensino"; “Implicações do mundo virtual na realidade escolar", "Ciberbullying”, "Transformação do olhar docente", "Conhecimento das comunidades virtuais", "Introdução às tecnologias digitais", "Desdobramentos na educação básica"; "Políticas de acesso e permanência das tecnologias nos processos formativos", "Desmistificação do uso das novas tecnologias nas práticas docentes". Associada à sistematização das questões nos cartazes, durante a discussão, os participantes colocaram suas inquietações sobre o modo como as novas gerações usam as tecnologias em seu cotidiano e como as interações na internet afetam a vida do estudante, refletindo-se no contexto da sala de aula. Lèvy (1999), quando aborda as questões que envolvem a cibercultura, denota que esse movimento traz mudanças no modo de aprender, que deveriam, a seu ver, já a partir do final da década de 1990, modificar as estruturas educacionais, fomentando a inteligência coletiva e novos processos de produção de saberes. No entanto, conforme afirma Sibilia (2012), a escola se mantém como um aparato da modernidade, seguindo os mesmos preceitos, as mesmas formas de controle e praticamente a mesma função com a qual foi pensada em seus primórdios. Tal fato se contrasta com as linguagens dinamizadas na contemporaneidade, nos processos espontâneos e informais de aprendizagem que se configuram na existência humana e nas relações sociais estabelecidas.

As inquietações e constatações refletidas na roda de conversa sobre este ponto foram muito contundentes e se mostraram bastante presentes nas falas e na sistematização da temática com vistas ao que os participantes consideram como importante de ser discutido na formação de professores, expressando uma percepção de que desejam compreender como podem ser trabalhados caminhos educacionais articulados às tecnologias.

Inerente a essa discussão, surgiram os índices: "Formação docente"; "A incorporação da tecnologia na formação docente"; "O impacto da tecnologia na formação de professores"; “Currículo e tecnologias". De certo modo, entendemos que o processo de formação docente já está em pauta a partir da própria proposta da roda de conversa e da atividade de 
sistematização, no entanto, os participantes, em suas construções, deixaram explicitada a necessidade da discussão da própria formação em diálogo com as questões da conectividade e das múltiplas linguagens na aprendizagem da profissão, colocando a necessidade de preparação do docente para lidar com as questões culturais contemporâneas de atuação social dos alunos, viabilizando práticas inovadoras e contextualizadas aos interesses e aptidões mais desenvolvidas pelas novas gerações. Contudo, precisamos reafirmar que não basta a aquisição de técnicas para o uso de equipamentos, o que poderia conduzir uma pessoa que pensa de forma linear e tradicional a dar ênfase ao treinamento, por exemplo. Tal perspectiva não corresponde ao trabalho de formação docente comprometido com a autonomia, a formação crítica, de modo a que os professores e alunos sejam sujeitos interagentes e não interagidos (CASTELLS, 2002). Não se trata de preparar mão de-obra para execução de tarefas pensadas por outros, como muitos projetos “inovadores" propõem. Uma pedagogia inovadora dialoga com as tecnologias buscando a formação de pessoas para entender mais e melhor o mundo, construir alternativas que possibilitem interconexões culturais inclusivas da multiplicidade humana. Para compreender a influência desse mundo conectado nas vidas de professores e estudantes da Educação Básica, não podemos ficar prisioneiros do como usar as mídias nos processos pedagógicos, mas ao não trabalhar com as mesmas nestes processos, vamos gerando um hiato cada vez mais amplo entre o que vivenciam os estudantes de diferentes origens em suas vidas e os processos de construção e sistematização de conhecimentos propostos pela educação escolar.

Essa questão fica clara também nas representações dos participantes da roda, quando produzem as temáticas e índices: "Tecnologias Midiáticas e a formação do leitor crítico", Leitor x Ledor", "Processamento de informações"; "Transformação da realidade", "Participação coletiva". Esses pontos foram abordados de modo bastante interessante no debate, a partir do entendimento de que é necessário que o professor seja mediador do estudante no sentido de ensiná-lo a ler as mídias, a estabelecer relações e parâmetros críticos de apropriação dos recursos tecnológicos e das informações e conhecimentos veiculados nos contextos midiáticos. Denotou-se o conhecimento sobre as potencialidades das linguagens no mundo cibernético e a necessidade de que possamos manipular as informações e conteúdos no sentido de não sermos reféns das redes de informação, mas criadores e detentores do processo de produção de saberes. Nesse sentido, denotamos como foi tratada a questão da "cultura hacker" (PRETTO, 2017), destacando-se o papel da educação nesse processo de emancipação do sujeito na utilização das redes. A cultura hacker dialoga com uma perspectiva contrária ao consumismo e ao individualismo tão presentes na cultura contemporânea. Preconiza uma 
apropriação do ciberespaço sem a tutela, mapeamento e monopólio de grandes corporações com interesse mercadológico com base na exploração, enraizado no processo de colonização. Propõe o acesso, uso e compartilhamento livre e autônomo dos conhecimentos disponibilizados na rede, propiciando situações nas quais os humanos são percebidos como interagentes e não apenas como consumidores acríticos, interagidos pelas mídias eletrônicas. Neste sentido, as instituições educativas devem estimular a troca e exploração livre de informações, numa produção coletiva e compartilhada de saberes, mediada pelo uso da rede.

As discussões e sistematização também apontaram para os seguintes temas e índices: "Introdução às tecnologias digitais", "Conceitos contemporâneos"; "Inclusão social"; "Acesso às tecnologias", "Políticas Públicas", "Qualidade no acesso", "Implicações no cotidiano"; "Políticas de acesso e permanência das tecnologias nos processos formativos".

Os pontos levantados problematizam questões basilares sobre a temática, demonstrando que as representações dos participantes expressam tanto a necessidade de ampliação do conhecimento sobre as tecnologias digitais, suas implicações na vida cotidiana dos indivíduos e suas repercussões nos processos educacionais quanto na consciência sobre a necessidade de políticas que garantam a igualdade de acesso à rede e equipamentos, promovendo inclusão social e digital. A questão que perpassa a realidade de muitos dos participantes e de grande parcela da população brasileira é a grande dificuldade de conexão com a internet nas regiões onde residem ou estudam. Para além disso, o uso majoritário de equipamentos é feito mediante o uso de aparelhos celulares - os smartphones - que, se por um lado permitem maior mobilidade e "portabilidade", por outro apresentam uma limitação maior de recursos informacionais, tais como relacionados à capacidade de memória para armazenamento e dinamização de conteúdos e aplicativos. Sabemos que os aparelhos celulares mais modernos e de última geração apresentam características e atributos mais avançados do que muitos computadores e tablets, por exemplo, no entanto, o custo não é acessível à população de média e baixa renda, o que acaba por segregar e excluir muitas pessoas de um acesso mais amplo às possibilidades encontradas nessas mídias. Nesse sentido, entendemos que os artefatos e as redes são limitadores quando se sabe que muitas vezes as condições de conectividade e os recursos são muito parcos. Na escola, apesar das condições que muitas apresentam de terem laboratórios de informática e possuírem equipamentos, o acesso e as condições de permanência e ampliação de possibilidades não potencializam o trabalho. Esses pontos, portanto, nos permitem vislumbrar que, além da falta de formação inicial e continuada em diálogo com as múltiplas linguagens do mundo conectado, há falta de estrutura que possibilite que a escola dialogue de maneira mais rica com as questões 
interpostas pela contemporaneidade. Nesse sentido, os participantes apontam que, para além de ações pontuais, existe a necessidade de uma política pública que garanta ou ao menos estabeleça a estruturação e manutenção das condições de veiculação de projetos com tecnologias nos processos formativos, a fim de ampliar espaços e estratégias de aprendizagem.

Os resultados e análises indicam que há muito a se caminhar no sentido de desenvolvermos práticas inovadoras na educação básica e no ensino superior.

Os diálogos estabelecidos na roda de conversa apontaram ricos elementos para que haja continuidade desse trabalho na formação de professores, de modo que mais questões sejam suscitadas e novos caminhos apontados.

\section{Pedagogias inovadoras nos cursos de licenciatura: propostas}

O trabalho que vem sendo desenvolvido na FEUFF mediante as iniciativas apresentadas nesse trabalho vem fustigando certezas e provocando, nas autoras, movimentos instituintes no/do fazer pedagógico. Tal mobilização acaba por gerar processos que se articulam com nossa visão de pedagogia inovadora: aquela que demanda que o professor saia do centro do processo e se perceba como um sujeito que não é mais um transmissor de saberes, quando o professor se assume como um mediador, um provocador do pensar na produção de conhecimentos colaborativos.

Diante do que temos desenvolvido, muitas potencialidades têm se apresentado, indicando a necessidade de continuação e ampliação do alcance de nossas ações, mediante trabalhos de pesquisa, ensino e extensão.

Sob essa perspectiva, temos como horizonte a realização de uma pesquisa ampla, de modo que alcancemos a representatividade de um grande percentual de estudantes de licenciatura da UFF. Entendemos como pontos importantes e horizontes possíveis: realizar uma pesquisa exploratória, mediante a aplicação de survey, com alunos e alunas das licenciaturas por meio das disciplinas do Núcleo Comum das Licenciaturas (Didática, Psicologia da Educação, Organização da Educação no Brasil e Pesquisa e Prática Educativa), que são ofertadas pela FEUFF a fim de levantar dados e estruturar ações formativas; estender a pesquisa a professores das disciplinas oferecidas pela Faculdade de Educação aos licenciandos; criar espaços para amplificar o debate sobre o tema (promover seminários, rodas de conversa, congressos); tensionar junto às coordenações de cursos de licenciatura o debate sobre a oferta de disciplinas presenciais com o uso de recursos informacionais, tendo em vista 
a possibilidade de interação também de ambiente virtual de aprendizagem; estimular nas práticas educacionais da formação docente a produção de materiais didáticos que se utilizem de tecnologias digitais; criar disciplinas optativas, eletivas e atividades complementares que utilizem linguagens diferenciadas das tradicionais, valorizando e colocando em perspectiva os aspectos relacionados às perspectivas da interconectividade, da inteligência coletiva e das ações em rede; estimular atividades de partilha e produção de conhecimento entre alunos e alunos-professores utilizando ferramentas e ambientes virtuais; criar mecanismos que estimulem os docentes das disciplinas obrigatórias a utilizar com seus alunos o Sistema de Informação que a Universidade oferece, explorando de forma mais ampla os recursos digitais disponibilizados; produzir pequenos vídeos com orientações para docentes sobre como usar em sala de aula alguns programas e aplicativos com seus alunos; estimular os alunos a consultarem, produzirem e postarem suas produções em portais educacionais de livre acesso (tais como o eduCAPES, etc.).

Essas iniciativas estão em perspectiva enquanto fruto do que já tem sido feito, dos diálogos que têm sido construídos e das ações implementadas no contexto do Curso de Pedagogia e da Faculdade de Educação da UFF.

As formulações desenvolvidas no texto nos mostraram indícios do tipo de formação que os estudantes estão a nos demandar, os debates que veem como prementes no seu processo de formação profissional.

Diante do que vimos e ouvimos, temos a consciência de que uma ação pedagógica inovadora, que dialogue com as múltiplas linguagens no contexto do mundo conectado prevê como primordiais a horizontalidade nas relações educacionais, a inclusão, a potencialização das experiências instituintes e o processo de emancipação humana. Munidas dessas ferramentas, estaremos potencializando práticas que possam superar e dialeticamente criar novos desafios para um projeto de formação de professores comprometido com a autonomia, a democracia e a igualdade.

\section{REFERÊNCIAS}

CASTELLS, M. A sociedade em rede. São Paulo: Paz \& Terra, 2002.

CASTELlS, M. A Era da informação: economia, sociedade e cultura. v. I. 6. ed. São Paulo: Paz e terra, 1999.

CASTELLS, M. Educação, cultura e tecnologia: a escola do século XXI. Conferência proferida no Seminário Internacional Educação, Cultura e Tecnologia: a escola do 
Século XXI. Niterói: Fundação Arte; Prefeitura Niterói, julho/2019. Disponível em: https://www.facebook.com/pg/PrefeituraMunicipaldeNiteroi/posts/?ref=page_internal. Acesso em: jul. 2019.

COARACY, L. L.; ALVES, W. B. As tecnologias digitais e a escola: pesquisando o cotidiano. In: COLÓQUIO INTERNACIONAL EDUCAÇÃO, CIDADANIA, EXCLUSÃO CEDUCE, 5., 2018, Campina Grande. Anais [...]. Campina Grande, PB: Editora Realize, 2018. Disponível em:

http://www.editorarealize.com.br/revistas/ceduce/trabalhos/TRABALHO_EV111_MD1_SA6 _ID1154_03062018232708.pdf. Acesso em: jul. 2019.

CUNHA, M. I. Inovações na educação superior: impactos na prática pedagógica e nos saberes da docência. Revista Em Aberto, v. 29, n. 97, p 87-101, set./dez. 2016.

DOMINICK, R. dos S. e ALVES, W. B. Inclusão digital e inovação pedagógica: diálogo necessário. Revista Ibero-Americana de Estudos em Educação, v. 13, n. esp. 2, set. 2018. Disponível em: https://periodicos.fclar.unesp.br/iberoamericana/article/view/11647. Acesso em: jun. 2019.

DOMINICK, R. dos S., BARBIRATO, P. F. de B., FURTADO, E. B., CONCEIÇÃO, C B. da, VIERA, A. C. M. M., OLIVEIRA, T. D. de. Inovações pedagógicas e cultura da partilha na formação docente. In: REUNIÃO ANUAL DA SBPC, 70., 2018, Maceió. Anais [...]. Maceió, AL: UFAL, 2018. Disponível em:

http://www.sbpcnet.org.br/livro/70ra/trabalhos/resumos/3149 1663c956f1f2858262ca035546 37e4d57.pdf. Acesso em: jun. 2019.

DOMINICK, R. dos S.; SILVA, C. de F. Relatório das ações e da produção de 2012 do Projeto de Pesquisa As "artes de fazer" a educação em ciclos: diálogos entre tecnologias na formação de Pedagogos II. Niterói: UFF-PROPPi, 2013. Disponível em: https://www.dropbox.com/s/iikt91d4wajgiu0/Cinthia\%20relatorio_final_PIBIC\%201509.\%20doc2013.doc?dl=0. Acesso em junho/ 2019.

FIORIN, J. L. Introdução ao pensamento de Bakhtin. São Paulo: Ática, 2006.

FRANCO AVELLANEDA, M.; SÁENZ RODRÍGUEZ, M. Del P. Dimensiones educativas de la tecnología social. Revista Educación y Pedagogía, [S.1.], n. 62, p. 63-77, jan. 2013. ISSN 0121-7593. Disponível em:

http://aprendeenlinea.udea.edu.co/revistas/index.php/revistaeyp/article/view/14110/12494. Acesso em: jul. 2019.

FREITAS, G. L. O estado da arte das discussões sobre currículo na pós-moderna sociedade da informação: estudo de caso e análise de conteúdo da produção dos pesquisadores em educação no período de 2001 a 2011. 2015. 463 f. Tese (Doutorado em Ciências da Educação) - Universidade da Madeira, Portugal, 2015.

FREIRE, P. Pedagogia da esperança: um reencontro com a Pedagogia do oprimido. Rio de Janeiro: Paz e Terra, 1992. Disponível em:

https://igituma.uma.pt/bitstream/10400.13/1509/1/DoutoramentoGeorgeteFreitas.pdf. Acesso em: maio 2019. 
HERNÁNDEZ, F.; VENTURA, M. A organização do currículo por projetos de trabalho. Trad. Jussara Haubert Rodrigues. 5. ed. Porto Alegre: Artes Médicas, 1998.

INEP (Instituto Nacional de Estudos e Pesquisas Educacionais Anísio Teixeira). Resumo Técnico: Censo da Educação Básica 2018 [recurso eletrônico]. Brasília: Instituto Nacional de Estudos e Pesquisas Educacionais Anísio Teixeira, 2019. Disponível em

http://download.inep.gov.br/educacao_basica/censo_escolar/resumos_tecnicos/resumo_tecnic o_censo_educacao_basica_2018.pdf. Ácesso em: maio 2019.

IPEA. Atlas da violência 2019. Brasília, Rio de Janeiro, São Paulo: Fórum Brasileiro de Segurança Pública 2019. Disponível em:

http://www.ipea.gov.br/atlasviolencia/download/12/atlas-2019. Acesso em: maio 2019.

LEVY, P. Cibercultura. São Paulo: Editora 34, 2010.

PRETTO, N. Formação de professores exige rede! Revista Brasileira de Educação, Rio de Janeiro, n. 20, p. 121-131, maio/jun./jul./ago. 2002. Disponível em:

https://www.redalyc.org/pdf/275/27502010.pdf. Acesso em: jul. 2019.

PRETTO, N. Educações, culturas e hackers: escritos e reflexões. Salvador: EDUFBA, 2017. Disponível em: novolivrode.pretto.info. Acesso em: jul. 2019.

SANTAELLA, L. Comunicação ubíqua: repercussões na cultura e na educação. São Paulo: Paulus, 2013.

SANTOS, E. T. A formação dos professores para o uso das tecnologias digitais nos GTs Formação de professores e Educação e comunicação da ANPED - 2000 A 2008. In: REUNIÃO ANUAL DA ANPED, 32., 2009, Caxambu. Anais [...]. Caxambu, 2009. Disponível em: http://www.anped.org.br/sites/default/files/gt08-5899-int.pdf. Acesso em: maio 2019.

SIBILIA, P. Redes ou paredes: a escola em tempos de dispersão. Trad. Vera Ribeiro. Rio de Janeiro: Contraponto, 2012.

SILVA, M. M. e. Cultura de paz: reflexões sobre o caráter restaurativo da pedagogia social. In Revista da Pedagogia Social, Niterói, v. 7, n. 2, 2019. Disponível em:

http://www.revistadepedagogiasocial.uff.br/index.php/revista/article/view/183. Acesso em: jul. 2019.

SILVA, M. M. e. Novas tecnologias e múltiplas linguagens na formação docente. VII Seminário Internacional de pesquisa em mídia e cotidiano. In: SEMINÁRIO INTERNACIONAL DE PESQUISA EM MÍDIA E COTIDIANO, 7., 2018, Niterói. Anais [...]. Niterói, RJ: PPGMC/UFF, 2018. Disponível em:

http://www.ppgmidiaecotidiano.uff.br/site/wp-content/uploads/2018/10/Anais-2018-PPGMCArtigos-Completos-GT1.pdf. Acesso em: jul. 2019.

SCHÖN, D. O praticante reflexivo: como os profissionais pensam em ação. Nova York: Livros Básicos, 1983. 
WARSCHAUER, C. A roda e o registro: uma parceria entre professor, alunos e conhecimento. 3. ed. São Paulo: Paz e Terra, 2001.

\section{Como referenciar este artigo}

DOMINICK, R. dos S.; ALVES, W. B.; SILVA, M. M. e. Desafios na Formação de Professores em um Mundo Conectado: representações, práticas e linguagens inovadoras. Revista Ibero-Americana de Estudos em Educação, Araraquara, v. 15, n. esp. 2, p. 16291651, ago. 2020. e-ISSN: 1982-5587. DOI: https://doi.org/10.21723/riaee.v15iesp2.13836

Submetido em: 30/08/2019

Revisões requeridas: $30 / 11 / 2019$

Aprovado em: 02/02/2020

Publicado em: 01/08/2020 